\title{
A Aberração Carcerária à Moda Francesa*
}

\author{
Loï Wacquant
}

$\mathrm{E}$ m março de 2003, o Ministério da Justiça francês lançou pela televisão uma campanha publicitária a fim de melhorar a imagem da administração penitenciária e assim atrair os 10 mil guardas que urgia recrutar para atender à previsível explosão da população carcerária. Três meses depois, havia mais de 60 mil presos para 48 mil lugares, recorde absoluto desde o fim da Segunda Guerra Mundial. Insalubridade; deterioração dos locais; promiscuidade extrema; falta de higiene; carência de pessoal e ausência flagrante das atividades de formação e de trabalho, reduzindo a missão de "reinserção" a mero slogan vazio e cruel; congestionamento nos locais de visita; avanço dos movimentos de reivindicação; e aumento dos incidentes graves e dos suicídios (cujo número duplicou em vinte anos) eram então objeto de protestos unânimes dos sindicatos de agentes penitenciários, de associações de advogados, do Conselho Nacional dos Tribunais, das associações humanitárias, das famílias de detentos, e dos militantes e pesquisadores da área penal ${ }^{1}$. Nada disso logrou reação da parte das autoridades, que chegaram a reduzir ao mínimo os tradicionais indultos presidenciais de 14 de julho para demonstrar a firme vontade

\footnotetext{
* [A tradução do original em francês "L'Aberration Carcerale a la Française" é de Estela Abreu.]

DADOS - Revista de Ciências Sociais, Rio de Janeiro, Vol. 47, n-2, 2004, pp. 215 a 232.
} 
de lutar contra o que o Chefe do Estado - que entende do assunto chamou com rancor de "impunidade".

No final de janeiro de 2004, o Comitê Europeu de Prevenção à Tortura publicou um relatório desanimador sobre o "tratamento desumano e degradante" aplicado aos detentos franceses, amontoados em condições de superpopulação quase feudais - cinco em uma cela de doze metros quadrados em certas prisões - e sobre o desprezo dos direitos fundamentais, a começar pelo direito à cela individual, estipulado pela Lei de 15 de junho de 2000 para os réus com processos ainda sem trânsito em julgado, e cuja aplicação, sempre adiada, descumpre o compromisso do país perante o Conselho da Europa (direito este estabelecido em 1968 e reafirmado em 1975, que deveria levar à individualização da pena, mas nunca respeitado pela administração penitenciária). Esse relatório repercute os que foram feitos no início de 2000 por três comissões nomeadas pela Assembléia Nacional, pelo Senado e pelo ministro da Justiça, unânimes a denunciar a distorção do sistema penitenciário francês que resvala para o tipo de "prisão 'pátio dos milagres'" onde vigoram "o arbítrio penitenciário" e a "lei do mais forte", chegando os senadores, unânimes, a falar de "humilhação para a República"2. Um mês depois, o ministro da Justiça, sr. Perben, respondeu com arrogância às críticas dos juristas europeus afirmando que a França passa apenas por um atraso na construção de novas prisões, o que em breve estará sanado. E acrescentou que, com 98 detentos / 100 mil habitantes, o país ainda está abaixo da média já que em outras nações européias o número de encarceramentos chega a ser um terço superior a esse ${ }^{3}$.

Tudo isso porque o governo de Jean-Pierre Raffarin - depois do de Jospin - transformou o zelo policial e o rigor penal em fortes argumentos eleitorais, e até em dogma político. Resultado: em dois anos, houve um aumento de 13 mil presos, sejam eles condenados ou réus. Aumento de recursos e intensificação das ações policiais nas "zonas sensíveis"; pressão burocrática e política sobre os juízes a fim de aumentar as penas e acelerar os processos (um terço das detenções procede de intimações para comparecimento imediato, contra um quarto de detenções na década anterior); ampliação generalizada do recurso à prisão e endurecimento das penas bem como das disposições relativas à detenção provisória, doravante estendida aos adolescentes de 13 a 16 anos para delitos simples; restrição da redução das penas e queda do livramento condicional e do regime semi-aberto: tudo con- 
corre para inflar a população colocada atrás das grades. Se a França continuar nessa via, em menos de cinco anos seus efetivos carcerários estarão duplicados, ou seja, uma progressão duas vezes mais rápida que a dos Estados Unidos no auge da bulimia penitenciária da década de 80, que os tornou campeões mundiais da detenção (700 presos/100 mil habitantes). Naquilo em que a esquerda dita plural praticava uma incriminação disfarçada e vergonhosa da miséria, a direita republicana assume plenamente, por meio de um vigoroso e enfático aparelho repressivo, sua opção de conter os distúrbios e desordens sociais que se acumulam nos bairros dos excluídos, que vivem solapados pelo desemprego maciço e pelo emprego informal. Mostrar a luta contra a delinqüência das ruas como um permanente espetáculo moral permite aos dirigentes atuais (como aos anteriores) reafirmar simbolicamente a autoridade do Estado no momento exato em que se percebe sua impotência no campo econômico e social. Essa encenação de segurança também lhes dá a esperança de atrair uma camada de eleitores fascinados pelo programa autoritário e xenófobo do Front National. E quando os resultados das urnas decepcionam, como ocorreu com o governo da esquerda plural na eleição municipal de 2001 e com a direita majoritária nas eleições regionais do inverno de 2004, só resta intensificar a repressão penal, e subordinar mais estreitamente o funcionamento da administração penitenciária ao da Justiça, e a política judiciária ao ativismo desenfreado da polícia.

\section{A PRISÃO COMO ASPIRADOR DA ESCÓRIA SOCIAL}

Utilizar a prisão como "aspirador social" para limpar as escórias das transformações econômicas em curso e retirar do espaço público o refugo da sociedade de mercado - os pequenos delinqüentes ocasionais, os desempregados e os indigentes, os sem-teto e os sem documentos, os toxicômanos, os deficientes e doentes mentais deixados de lado por incúria da proteção sanitária e social, assim como os jovens de origem popular condenados a uma (sobre)vivência feita de expedientes e de furtos para suprir a precariedade dos salários - é uma aberração no sentido exato do termo, isto é, segundo a definição do Dicionário da Academia Francesa de 1835, uma "falha de imaginação" e um "erro de juízo" tanto político quanto penal.

Aberração, primeiro, pois a evolução da criminalidade na França não justifica em nada o crescimento fulgurante da população prisional após o decréscimo moderado de 1996-2001. Como já se constatou em 
outro trabalho (Wacquant, 2004b), os arrombamentos, furtos de veículos e de pequenos objetos (que constituem três quartos dos crimes e delitos registrados pelas autoridades) estão diminuindo regularmente desde 1993; os homicídios e lesões corporais seguidas de morte refluem desde 1995, segundo os levantamentos do Institut National de la Santé et de la Recherche Médicale - INSERM (e, segundo dados da polícia, desde 1984); e o aumento de roubos que obnubila a mídia, além de ser sobretudo "violência" verbal (insultos, ameaças), decresce constantemente há vinte anos ${ }^{4}$. Não houve um surto de delitos que justifique automaticamente a confusa intervenção do Estado nesse ponto. Além disso, ao invés da impressão esmagadora criada pela recente obsessão tanto da televisão quanto da imprensa sobre o assunto, a preocupação com segurança hoje não é nova nem excepcionalmente aguda na população. As sondagens de rua mostram que o medo do crime (medido pela adesão à frase "não me sinto em segurança") permanece relativamente estável nas duas últimas décadas, exceto em três modestos picos em 1978, 1983-1985 e 1999-2001, e, depois destes três anos de alta, seu nível de 2001 iguala-se ao de 1978 (Robert e Pottier, 1997; Robert, 2002:13-16, para o período 1995-2001). Enfim, sabe-se que o medo do crime não tem muito a ver com sua incidência real, já que a imagem dominante de uma violência anônima que atingiria todo mundo em toda a parte, e em especial os mais vulneráveis (idosos, mulheres e transeuntes comuns), não corresponde de modo algum à distribuição socioespacial dos delitos. Assim, a metade dos franceses, que declararam ter sofrido um ato de violência em 1996 (ou seja, uma pequena minoria correspondente a 5\% de adultos de mais de 25 anos), conhecia seu agressor; $3 \%$ dos entrevistados haviam sido atacados na rua, $10 \%$ em casa e $13 \%$ no local de trabalho; as vítimas jovens de 25-29 anos eram três vezes mais numerosas que os sexagenários; os homens mais numerosos que as mulheres (mesmo com idêntica freqüência de saídas); e, por fim, o medo do crime a domicílio era tão comum na zona rural quanto na cidade (10\%) e tão forte em residência individual quanto em moradia coletiva, embora os delitos fossem mais freqüentes no segundo caso (Crenner, 1996:1-4). Em suma, não foi tanto a criminalidade que mudou nos últimos anos e sim a maneira como políticos e jornalistas, porta-vozes dos interesses dominantes, vêem a delinqüência de rua e as populações que supostamente a alimentam. Os mais visados são os jovens das classes populares, imigrantes magrebinos confinados na periferia retalhada há três décadas pela desregulação econômica e pela omissão urbana 
do Estado, periferia transformada em chaga que a cataplasma administrativa da "política da cidade" tentou, sem êxito, cauterizar.

Aberração, também, porque a criminologia comparada confirma peremptoriamente que não existe em lugar nenhum - em nenhum país e em nenhuma época - correlação entre a taxa de encarceramento e o nível de criminalidade (Christie, 2003). É costume citar os Estados Unidos como exemplo de nação que teria recentemente conseguido diminuir as infrações pela ênfase dada à repressão penal. Mas já foi constatado em estudo anterior (Wacquant, 2004b) que todas as análises sérias a esse respeito concluem, ao contrário, que a política policial de "tolerância zero" alardeada por Nova Iorque e o seu número de presos quatro vezes maior em 25 anos só tiveram um papel decorativo na baixa dos litígios, resultante da conjuminação de fatores econômicos, demográficos e culturais. Seja como for, a prisão só atende, na melhor hipótese, a uma ínfima parcela da criminalidade e até da mais violenta: nos Estados Unidos, que dispõem de um aparato policial e carcerário grotescamente superdimensionado, em razão do descarte sucessivo nas diferentes etapas dos trâmites penais, os 4 milhões de delitos mais sérios contra as pessoas contatadas em 1994 pelas pesquisas de vitimização (homicídios, ferimentos e lesões corporais de natureza grave, roubos, estupros) equivalem a menos de 2 milhões de queixas à polícia, que motivaram 780 mil detenções que, por sua vez, só levaram afinal a 117 mil prisões efetivas, ou seja, $3 \%$ dos atos perpetrados, deixando intactas 97\% das violências criminosas graves (Rand, 1997; Federal Bureau of Investigation, 1997; Brown e Langan, 1998). O mesmo "efeito funil" é observado no funcionamento da justiça penal na França, onde menos de $2 \%$ dos processos levados a tribunal redundam em pena de prisão ${ }^{5}$. Percebe-se como a prisão está inapta para lutar contra a pequena e média delinqüência e, com maior razão, contra as "incivilidades" que, na maioria, nem constam do Código Penal (olhares intimidativos, atitude agressiva, insultos, empurrões, ajuntamentos e baderna em locais públicos, pequenos vandalismos etc.). Mais uma prova de que a repressão judiciária é ineficaz na França como em outros lugares é esta: as condenações de menores à prisão em regime fechado subiram de 1.905, em 1994, para 4.542, em 2001, e o número de detenções provisórias de adolescentes praticamente dobrou, passando de 961 a 1.665; com tudo isso, a delinqüência juvenil continuou aumentando nesse período, segundo declarações oficiais. 
Em terceiro lugar, o recurso automático do encarceramento para debelar as desordens urbanas é um remédio que, em muitos casos, só agrava o mal que pretende sanar. Instituição baseada na força e agindo à margem da legalidade (apesar das reiteradas recomendações de muitas comissões oficiais, o detento francês não dispõe de estatuto jurídico ${ }^{6}$, a prisão é um cadinho de violências e de humilhações cotidianas, um vetor de desagregação familiar, de desconfiança cívica e de alienação individual. E, para muitos presos implicados ligeiramente em atividades ilícitas, é uma escola de formação, para não dizer de "profissionalização", na carreira do crime. Para outros, o que também é péssimo, o cárcere é um abismo sem fundo, um inferno alucinante, a extensão da lógica de destruição social que eles já viviam fora do presídio, agora, acrescida da aniquilação pessoal (Rouillan, 2004; Lucas, 1995). O funcionamento dos presídios caracteriza-se pela completa disjunção entre a pena proferida pelo discurso judiciário e a que é de fato aplicada, o que provoca "nos detentos uma descrença radical aliada a um profundo sentimento de injustiça" (Chantraine, 2004:249) - e o caos da vida na prisão ainda prolonga e acentua a experiência da arbitrariedade judiciária ${ }^{7}$. A história penal mostra, além disso, que em nenhum momento e em nenhuma sociedade a prisão cumpriu sua suposta missão de recuperação e reintegração social, de acordo com a óptica de redução da reincidência. Como observou laconicamente um agente penitenciário, "a reintegração não se dá na prisão. Aí já é tarde demais. Para reintegrar é preciso dar trabalho, igualdade de oportunidades, escola. Essa é que é a reintegração. Medidas de tipo 'social' podem ser tentadas, mas já pouco adiantam" (Chauvenet et alii, 1994:38). Sem contar que tudo - desde a arquitetura até a organização de trabalho dos guardas, passando pela pobreza de recursos institucionais (trabalho, formação, escolaridade, saúde), pela extinção deliberada do livramento condicional e pela ausência de medidas concretas de ajuda no momento da libertação - se opõe à suposta função de "reforma" do detento.

Finalmente, convém destacar - para aqueles que invocam o ideal de justiça social a fim de legitimar o recrudescimento da repressão nos bairros mais pobres a pretexto de que "a segurança é um direito, a insegurança é uma desigualdade social" atingindo prioritariamente os cidadãos menos favorecidos, como gostava de repetir o então primeiro-ministro Lionel Jospin ${ }^{8}$ - que a contenção carcerária atinge desproporcionalmente as categorias sociais econômica e culturalmente mais frágeis, $\mathrm{e}$ 
isso de modo mais duro por elas não disporem de recursos. Como seus homólogos de países pós-industriais, os detentos franceses provêm maciçamente das parcelas instáveis do proletariado urbano. Filhos de famílias numerosas (dois terços têm ao menos três irmãos ou irmãs), das quais se separaram muito jovens (um em cada sete deixou o lar antes dos 15 anos), são na maioria desprovidos de escolaridade (três quartos abandonaram a escola antes dos 18 anos, contra $48 \%$ da população masculina), o que os condena para sempre aos setores subalternos do mercado de trabalho. Uma metade é de filhos de operários e de empregados, e a outra é de operários (contra 3\% de filhos de executivos, que equivalem a $13 \%$ da população ativa nacional); quatro detentos em cada dez têm pai nascido no estrangeiro e $24 \%$ nasceram fora do território francês 9 . Ora, a prisão só contribui para intensificar a pobreza e o isolamento: $60 \%$ dos que deixam a prisão são desempregados, comparados com 50\% dos que entram; $30 \%$ não são ajudados nem atendidos por ninguém; mais de $25 \%$ não dispõem de dinheiro (menos de 15 euros) para arcar com as despesas ao serem soltos, e um em oito não tem moradia ao sair da prisão (Guillonneau et alii, 1998:1-4). Mesmo dentro dos estabelecimentos penitenciários, a trajetória e as condições de vida dos detentos apresentam fortes desigualdades de classe. Do registro de entrada e da destinação, passando pelas transferências, pelo acesso aos recursos internos e ao direito de progressão no cumprimento da pena, cada etapa do circuito prisional contribui para o empobrecimento cumulativo dos presos mais desfavorecidos em virtude da total prioridade que a gestão cotidiana dá ao imperativo de segurança (Marchetti, 2002:416-434). Ademais, o impacto danoso do encarceramento não age apenas sobre o detento mas também, e de modo mais insidioso e injusto, sobre sua família: deterioração da situação financeira, desagregação das relações de amizade e de vizinhança, enfraquecimento dos vínculos afetivos, distúrbios na escolaridade dos filhos e perturbações psicológicas graves decorrentes do sentimento de exclusão aumentam o fardo penal imposto aos pais e cônjuges de detentos (Dubéchot et alii, 2000; Comfort, 2002:467-499).

O argumento, habitualmente invocado pelos partidários da política punitiva, segundo o qual a inflação carcerária corresponde a uma redução automática da criminalidade pois "neutraliza" condenados que, atrás das grades, já não oferecem perigo, parece cheio de bom senso, mas, se bem examinado, revela-se ilusório, porque, quando 
aplicado à delinqüência de baixa periculosidade, o encarceramento desmesurado equivale a "recrutar" novos delinqüentes por efeito de substituição ${ }^{10}$. Assim, um pequeno traficante de drogas detido é imediatamente substituído por outro, contanto que haja uma demanda solvível para a mercadoria e uma expectativa de lucro. E, se esse substituto for um novato desconhecido, estará mais disposto à violência para se firmar e assegurar seu negócio, o que, afinal, redundará em mais criminalidade. Além disso, a prisão tem a característica de uma bomba social que aspira-e-expele: ela devolve à sociedade indivíduos capazes de cometer ainda mais delitos e crimes em virtude do corte sociobiográfico que a reclusão exerce; da carência de programas de "reinserção" durante e após o encarceramento; e da série de restrições, incapacidades e outros prejuízos decorrentes de uma passagem pela polícia. Pesquisa recente mostra que 52\% dos presos na França cometem uma (ou várias) infrações nos cinco anos seguintes à sua soltura e que a probabilidade de reincidência varia muito na razão inversa da severidade do primeiro delito: ela vai de $23 \%$ para os delitos sexuais contra crianças e $28 \%$ para os homicídios dolosos a $56 \%$ para a venda de drogas, $59 \%$ para o uso de drogas e a $75 \%$ para os furtos (Kensey et alii, 2004:1-4). Mesmo assim, nada é feito para interromper de fato o circuito crime-prisão-crime, a não ser o agravamento da pena para os reincidentes, embora se saiba que o efeito dissuasivo do encarceramento é praticamente nulo para os delitos menores.

Enfim, o encarceramento em grande escala induz um processo de mitridatização penal das populações que ele atinge regularmente, tornando-as pouco a pouco insensíveis à ação preventiva ou retributiva buscada pelas autoridades. Ao banalizar a repressão judiciária, o Estado esmaece o efeito que a cerca e apaga o estigma que lhe está associado, de tal modo que precisará sempre aumentar as "doses" de castigo necessárias para ajustar o comportamento dos que não se enquadram - fenômeno que, do ponto de vista da luta contra o crime, pode ser resumido em uma frase que soa bem aos ouvidos dos economistas liberais: "Prisão demais acaba com a prisão". Ultrapassado um certo limiar de penetração penal, a carga simbólica negativa da condenação inverte-se e a estada na cadeia torna-se distintivo de honra masculina e sinal valorizado de pertencimento ao grupo dos que estão destinados à cultura e à economia da rua (exemplos em Chantraine, 2004:85-103, para a França; e em Simon e Burns (1997) para os Estados-Unidos). Afinal, sorvendo um número sempre maior de indiví- 
duos, a prisão acaba se alimentando com seus próprios produtos, tal qual uma fábrica de reciclagem do rebotalho social que despeja na sociedade, a cada ciclo, substâncias cada vez mais nocivas ${ }^{11}$.

\section{COMO ESCAPAR DA CILADA DA SEGURANÇA}

É portanto aberrante, do ponto de vista penal e político, discriminar deliberadamente de um lado a política da "insegurança" criminal e de outro o aumento de insegurança social que alimenta a primeira, tanto na realidade quanto nas representações coletivas. É também insensato pretender tratar os ilícitos menores com um instrumento tão grosseiro e ineficaz como é a prisão. Urge considerar plenamente os efeitos judiciários perversos e os danos sociais causados pela intensificação indiscriminada da repressão penal e pela extensão incontrolada de um aparelho prisional já sobrecarregado que, no funcionamento cotididano, desqualifica os ideais de justiça e igualdade que supostamente deve defender. Para não resvalar em uma escalada penal sem fim e sem saída, é indispensável reconectar a discussão sobre a delinqüência com a ampla questão social deste século: o aparecimento do trabalho dessocializado, vetor de insegurança social e de enfraquecimento material, familiar, escolar, sanitário e até mental. Pois ninguém consegue ordenar sua percepção do mundo social e conceber o futuro quando o presente está fechado e se torna uma luta diária e sem trégua pela sobrevivência ${ }^{12}$.

Não se trata de negar a realidade da criminalidade nem a necessidade de lhe dar uma resposta, ou melhor, respostas, inclusive penal, quando essa é a adequada. Trata-se de entender melhor sua gênese, sua fisionomia mutável e suas ramificações, "re-situando-a" no sistema completo das relações de força e de sentido que ela exprime, o qual ajuda a explicar não só sua forma e incidência, mas também as reações histéricas que provoca na conjuntura deste início de século. Para tal, convém parar com os discursos alarmistas e iniciar uma discussão racional e documentada sobre os ilícitos (plural), seus efeitos e significados. Essa discussão deve primeiro especificar por que ela se concentra em certas manifestações de delinqüência - mais nos corredores dos conjuntos habitacionais do que nos corredores dos hotéis da cidade, nos roubos de carteiras e de celulares do que nas negociatas da Bolsa e nas infrações à legislação trabalhista ou tributária etc. ${ }^{13}$. Deve distinguir os delitos e medir cada um deles com rigor e precisão, em vez de proceder por amálgama e por mais-ou-menos ${ }^{14}$, e evitar os ra- 
ciocínios e as reações elaborados a partir de casos extremos (por exemplo, designar o suicídio de um aluno como "violências escolares" e os "grupos mafiosos" como tráfico de entorpecentes nas imediações de um conjunto da periferia). Deve sair do imediato e da comoção da atualidade jornalística para distinguir com clareza as camadas superficiais e as profundas, as variações acidentais de um ano para o outro e as tendências a longo prazo; não confundir a subida da intolerância, do medo, ou da preocupação com o crime com o aumento do próprio crime. Mas, sobretudo, uma política inteligente sobre a insegurança criminal precisa reconhecer que os atos delinqüentes são o produto não de uma vontade individual autônoma e singular, mas de um conjunto de causas e de motivos múltiplos que se mesclam de acordo com várias lógicas (vandalismo, exibicionismo, alienação, transgressão, afrontamento à autoridade etc.) e, por isso, reclamam remédios bem diferentes e cuidadosamente coordenados. Estes remédios devem levar em conta a fraca eficácia congênita do aparelho penal e romper com a desgastada alternativa sugerida pela parelha prevenção/repressão, a fim de instaurar uma pluralidade de mecanismos de contenção e de oferta de oportunidades. Tudo isso por reconhecer que o tratamento policial e penal, que alguns apresentam hoje como panacéia universal, é em geral pouco aplicável e se revela muitas vezes pior que o mal, quando se contabilizam seus "efeitos colaterais".

As ciências sociais não se manifestam sobre esse assunto para "desculpar" este ou aquele comportamento, simplesmente porque elas não procedem da lógica do processo, cujo intento é absolver ou condenar. Seu objetivo é explicar e compreender, isto é, fornecer instrumentos de conhecimento comprovado que possam também se tornar instrumentos de uma ação inteligente na cidade. "Saber para prever, prever para poder", dizia Auguste Comte, pai da sociologia. A criminalidade é, em todas as sociedades, um problema sério demais para ser entregue aos falsos especialistas e aos verdadeiros ideólogos, e menos ainda aos policiais e aos políticos prontos para explorar o problema sem julgá-lo de forma justa nem saber dominá-lo de fato. Suas transformações exigem não a desistência, mas sim uma nova abordagem sociológica, a única que pode salvar do pornografismo da segurança, o qual reduz a luta contra a delinqüência a um espetáculo ritualizado servindo apenas para saciar os "fantasmas da ordem" do eleitorado e para reafirmar simbolicamente a autoridade viril de quem decide no âmbito governamental. 
Tanto quanto o emprego desregulamentado, que alguns insistem em apresentar como uma necessidade natural (importada dos Estados Unidos) filha de uma "globalização" inelutável embora nem sempre desejável ${ }^{15}$, o recurso crescente ao braço policial e penitenciário do Estado para debelar as desordens sociais e mentais geradas pela instabilidade do trabalho não é uma fatalidade. Opor-se à incriminação da pobreza urbana e de seus corolários obriga a travar uma luta tríplice. Primeiro, no nível das palavras e dos discursos, a fim de frear os deslizes semânticos, na aparência anódinos, que comprimem e prescrevem o espaço do pensável e, portanto, do factível (por exemplo, limitando arbitrariamente o sentido da palavra "segurança" apenas à esfera criminal, desligada da segurança do emprego, da renda, da moradia etc.) e levam a banalizar o tratamento punitivo das tensões ligadas ao agravamento das desigualdades sociais (por exemplo, pelo uso de noções vagas e incoerentes como a de "violências urbanas") ${ }^{16}$. É imperativo a esse respeito que se submeta a importação das pseudoteorias fabricadas pelos think tanks americanos e seus seguidores europeus para justificar a expansão do Estado penitenciário a um severo controle alfandegário sob a forma de uma infalível crítica lógica.

Quanto à política e à prática judiciária, cabe também obstar à proliferação dos dispositivos que tendem a "ampliar" a rede penal; deve-se propor, sempre que possível, uma alternativa econômica, social, sanitária ou educativa mostrando como esta, em seu âmbito, contribui para tratar o problema pela raiz, ao passo que a contenção punitiva quase sempre só o agrava, principalmente porque, ocultando as causas, favorece-lhe o desenvolvimento. Convém nunca esquecer as condições e os efeitos destrutivos da prisão, não só sobre os detentos mas também sobre suas famílias e seu ambiente. Lembrar que a prisão não é um simples escudo contra a delinqüência, mas uma faca de dois gumes: um órgão de coerção que tanto ataca quanto gera o crime e que, quando tem um desenvolvimento exagerado, como nos Estados Unidos nos últimos 25 anos ou na União Soviética durante a era stalinista, transforma-se em vetor autônomo de pauperização e de marginalização ${ }^{17}$.

É também necessário defender a autonomia e a dignidade dos profissionais do braço social do Estado - o trabalhador social, psicólogo, professora, educador especializado, animador, crecheira, enfermeiro, médico para não incorrer no corporativismo. Esses profissionais devem exigir os recursos orçamentários e humanos indispensáveis ao cumpri- 
mento de sua missão, de toda a sua missão e nada além de sua missão ${ }^{18}$, isto é, recusar-se ao papel de auxiliar da polícia e da administração judiciária sob a alegação de uma melhor coordenação do serviço público e de eficiência burocrática. As sinergias entre os setores do Estado são, em princípio, desejáveis, mas resta saber qual delas impõe sua lógica, sua linguagem, seus critérios de ação, seu horizonte temporal e seus objetivos ${ }^{19}$ : o que se busca é aumentar a "segurança social" das famílias e dos indivíduos em dificuldade a longo prazo, de modo a conferir-lhes maior estabilidade e capacidade de vida - ou será que se procura produzir "segurança criminosa" a curto prazo (ou, pior ainda, sua encenação para a mídia) baixando à força as estatísticas registradas sobre a delinqüência e exibindo severidade paternalista com fins eleitoreiros? Que força do Estado vence nessa queda-de-braço permanente entre as duas modalidades possíveis da ação pública? $\mathrm{O}$ "lado esquerdo", que alimenta e sustenta, protege os desfavorecidos dos riscos da vida, reduz as desigualdades; ou o "lado direito", incumbido da manutenção da ordem, tanto moral e econômica quanto legal? Do setor policial e penal também: os agentes penitenciários devem defender a dignidade e a integridade de sua profissão, negando-se a exercer funções degradadas de atendimento social e sanitário que não lhes competem (como nas prisões em que o setor psiquiátrico passa a tratar os casos de patologia mental profunda que, por não terem sido assistidos no devido âmbito hospitalar, são levados à reclusão).

Enfim, é desejável que se estabeleçam contatos entre militantes e pesquisadores criminalistas e sociais, entre sindicalistas e membros de associações dos setores assistencial, educativo e sanitário, por um lado, e seus homólogos que se dedicam aos setores policial, judiciário e penitenciário. Essa sinergia ativista e científica deve firmar-se não apenas em âmbito nacional, mas em escala européia para otimizar os recursos intelectuais e organizacionais a serem investidos na luta permanente pela redefinição do âmbito e das modalidades da ação pública (Pedro, 2003). Há enormes jazidas de saber teórico e prático a serem exploradas e partilhadas em nível continental. Pois a verdadeira alternativa para não descambar na incriminação da miséria, leve ou rigorosa, é a construção de um Estado social europeu digno deste nome. Três séculos e meio depois de sua invenção histórica, o meio mais eficaz de conter a prisão continua sendo ainda e sempre o avanço dos direitos sociais e econômicos.

(Recebido para publicação em maio de 2004)

(Versão definitiva em junho de 2004) 


\section{NOTAS}

1. Há uma descrição detalhada e aflitiva sobre o estado atual das prisões francesas no Observatoire International des Prisons (2003).

2. Relatório do sr. Guy Canivet enviado a sra. Guigou, ministra da Justiça, em 6 de março de 2000; relatório do sr. Jacques Floch, no⒉521, entregue à Assembléia Nacional em 28 de junho de 2000; relatório do sr. Guy-Pierre Cabanel, noํ449, entregue ao Senado em 28 de junho de 2000.

3. O ministro da Justiça citava sobretudo as proporções acima de 130 detentos / 100 mil habitantes da Espanha e de Portugal. Ele omitiu os países que têm menos presos que a França, entre os quais, a Alemanha, a Áustria, a Suíça, os países nórdicos, a Bélgica, a Irlanda, a Grécia e até a Turquia (Mansuy, 2004:3-4). Quando a França tiver alcançado o líder britânico (que apresentava 143 detentos/100 mil habitantes em abril de 2004, após um crescimento de 55\% em uma década), ser-lhe-á ainda possível, na lógica desse raciocínio, comparar-se com países bem mais punitivos como a Eslováquia (165), Romênia (200), Polônia (224) e, enfim, Ucrânia (417) e Rússia (584).

4. Para uma análise mais minuciosa, consultar os capítulos relativos a essas infrações em Mucchielli e Robert (2002).

5. Os 5.461.024 processos recebidos pelos tribunais franceses em 2002 produziram 3.733.366 casos arquivados (seja por caracterização inadequada das infrações seja por falha de elucidação) e 1.350 .393 processos penais, dos quais mais de um terço (429.505) foram classificados como extintos (por motivo de desistência ou carência do queixoso, prejuízo de pouca monta, inimputabilidade do acusado em virtude de retardamento mental, responsabilidade da vítima etc.), ao passo que 289.483 desencadearam uma pena alternativa, para um restante de 624.650 processos sentenciados (ou seja, 11,4\% do número original). Levando em conta todas as jurisdições, essas sentenças levaram a 477.935 condenações penais, das quais 99.682 ordens de prisão em regime fechado e 1.355 penas de reclusão total, ou seja, uma "resposta carcerária" cobrindo 1,8\% dos casos levados a tribunal (101.037 divididos por 5,4 milhões; cf. Estatísticas do Ministério da Justiça, "Activité des Parquets en 2002", disponível em: <http://www. justice.gouv.fr/chiffres/penale03.htm>).

6. Sobre a fraqueza e a incoerência do direito carcerário francês, apesar de progressos verificados na década passada, ver Herzog-Evans (1998).

7. Assim como é documentado pelo relatório do Cimade [Service Oecuménique D’Entraide], Les Prétoires de la Misère. Observation Citoyenne du Tribunal Correctionnel de Montpellier, de 2004, e pelas crônicas correcionais de Simonnot (2003).

8. "Sécurité: Le Gouvernement Souhaite Étendre la Politique de Proximité" (Le Monde, 8/12/1999). Jean-Pierre Chevênement, o ministro do Interior que presidiu a conversão sobre a questão da segurança da esquerda governamental, gostava de destacar as "virtudes pedagógicas" da sanção penal e até do encarceramento ("La Répression a aussi une Vertu Pédagogique", Le Parisien, 30/3/2000).

9. Dados extraídos da pesquisa junto a 1.719 detentos de 23 casas de detenção e de cinco presídios, realizada pelo Institut National de la Statistique et des Études Écono- 


\section{Loïc Wacquant}

miques - INSEE e pela administração penitenciária no âmbito de um estudo mais amplo sobre a história familiar, cf. Cassan et alii (2000:1-4).

10. Sobre as zonas sombrias, efeitos perversos e outras conseqüências contra-intuitivas da filosofia "neutralizante" do encarceramento, é muito recomendável a leitura de Zimring e Hawkins (1995).

11. O peso crescente dos fatores endógenos na hiperinflação carcerária nos Estados Unidos foi mostrado por Caplow e Simon (1999:63-120).

12. Como havia demonstrado Pierre Bourdieu (1962:313-331) nos casos extremos dos subproletários argelinos durante a guerra de libertação nacional. A pertinência dessa análise para as situações de marginalidade urbana nas sociedades contemporâneas é evidente quando as descrições feitas por Stettinger (2003) são lidas.

13. Convém lembrar que o custo econômico da criminalidade de colarinho-branco é consideravelmente mais elevado que o da delinqüência comum e dos crimes violentos. Em 1996, o contravalor monetário das falsificações era estimado em 25 bilhões de francos, enquanto a fraude nas contribuições sociais somava 17 bilhões, contra 250 milhões para os roubos em lojas, 4 bilhões para os roubos de veículos e 11 bilhões para os crimes dolosos contra a vida. Nesse ano, o peso da fraude fiscal e alfandegária foi de 100 bilhões e o custo dos acidentes de tráfego foi superior a 39 bilhões (Palle e Godefroy (1999); foram consideradas as estimativas mais elevadas para cada uma das categorias de delitos). Desse ponto de vista, a prioridade do Estado deveria ser o respeito do código tributário e do código de trânsito. Mas atacar esses dois desvios de massa implicaria reconhecer a delinqüência do cidadão comum e impediria que a ação repressiva se concentrasse sobre a categoria "bode expiatório".

14. As evidentes insuficiências dos atuais instrumentos de medida no caso francês são mostradas por Tournyol du Clos (2002:25-34). É bastante improvável que o Observatório Nacional da Delinqüência, inaugurado em novembro de 2003 pelo ministro do Interior Nicolas Sarkozy, seja capaz de suprir essas carências porque, entre os 27 membros do seu conselho diretor, não há nenhum criminologista nem pesquisador de valor reconhecido (o único pesquisador universitário é Frédéric Ocqueteau, diretor da revista interna do Institut des Hautes Études de la Sécurité Intérieure IHESI, principal órgão de propaganda estatal sobre segurança), além de ser presidido pelo vendedor de conselho em "segurança urbana" Alain Bauer, cuja incompetência estatística é bem conhecida de todos.

15. Há uma corrosiva crítica empírica e teórica a essa crença central do neodarwinismo econômico dominante no texto de Esping-Andersen e Regini (2000).

16. A quem subestima a importância dessa luta ou a vê como preocupação de intelectual. Pierre Bourdieu lembra que "o mundo social é o lugar da luta a respeito de palavras que são graves - e até violentas - porque as palavras quase sempre determinam as coisas, e mudar as palavras, e de modo mais geral as representações [...], já é mudar as coisas" (1987:69).

17. Para uma demonstração minuciosa sobre o encarceramento punitivo dos moradores do gueto negro norte-americano no fim do século XX (cf. Wacquant, 2004a:cap. $3)$. 
18. Essa exigência concerne às lutas internas travadas pelos trabalhadores sociais a respeito dos objetivos e das modalidades de sua ação na era do desemprego de massa, e do assalariado esfacelado diante da diversificação dos cargos, da burocratização das tarefas, da ascensão da abordagem gerencial e do ressurgimento do trabalho voluntário (cf. Ion, 1998).

19. Um exemplo dessa luta entre justiça e trabalho social no âmbito da proteção da infância é dado por Serre (2001:70-82).

\section{REFERÊNCIAS BIBLIOGRÁFICAS}

BOURDIEU, Pierre. (1962), “La Hantise du Chômage chez L'Ouvrier Algérien. Prolétariat et Système Colonial". Sociologie du Travail, vol. 4, no 4, pp. 313-331. (1987), Choses Dites. Paris, Minuit.

BROWN, Jodi M. e LANGAN, Patrick A. (1998), State Court Sentencing of Convicted Felons, 1994. Washington, Bureau of Justice Statistics.

CAPLOW, Theodore e SIMON, Jonathan. (1999), "Understanding Prison Policy and Population Trends", in M. Tonry e J. Petersilia (eds.), Prisons. Chicago, University of Chicago Press, pp. 63-120.

CASSAN, Francine, TOULEMONT, Laurent e ANNIE, Kensey. (2000), “L'Histoire Familiale des Hommes Détenus". INSEE Première, no 706, pp. 1-4.

CHANTRAINE, Gilles. (2004), Par-delà les Murs. Expériences et Trajectoires en Maison $D^{\prime}$ Arrêt. Paris, PUF.

CHAUVENET, Antoinette, ORLIC, Françoise e BENGUIGUI, Georges. (1994), Le Monde des Surveillants de Prison. Paris, PUF.

CHRISTIE, Nils. (2003) [2000], L'Industrie de la Punition. Prison et Politique Pénale en Occident. Paris, Autrement.

COMFORT, Megan. (2002), “Papa's House': The Prison as Domestic and Social Satellite". Ethnography, vol. 3, no 4, pp. 467-499.

CRENNER, Emmanuelle. (1996), “Insécurité et Sentiment D’Insécurité". INSEE Première, no 001 , pp. 1-4.

DUBÉCHOT, Patrick, FRONTEAU, Anne e LE QUÉAU, Pierre. (2000), “La Prison Bouleverse la Vie des Familles de Détenus". CRÉDOC - Consommation et Modes de Vie, no 143 .

ESPING-ANDERSEN, Gösta e REGINI, Marino (eds.). (2000), Why Deregulate Labour Markets? Oxford, Oxford University Press.

FEDERAL BUREAU OF INVESTIGATION. (1997), Uniform Crime Report 1995. Washington, Government Printing Office. 


\section{Loïc Wacquant}

GUILLONNEAU, Maud, KENSEY, Annie e MAZUET, Philippe. (1998), “Les Ressources des Sortants de Prison". Les Cahiers de Démographie Pénitentiaire, no 5, pp. 1-4.

HERZOG-EVANS, Martine. (1998), La Gestion du Comportement du Détenu. Essai de Droit Pénitentiaire. Paris, L'Harmattan.

ION, Jacques. (1998), Le Travail Social au Singulier. Paris, Dunod.

KENSEY, Annie, TOURNIER, Pierre-Victor e ALMÉRAS, Christelle. (2004), “La Récidive des Sortants de Prison". Les Cahiers de Démographie Pénitentiaire, n-15, pp.1-4.

LUCAS, Claude. (1995), Suerte. La Réclusion Volontaire. Paris, Plon.

MANSUY, Isabelle. (2004), “Réponse au CPT: Circulez y'a Rien à Voir!”. Dedans Dehors, no 42 , pp. 3-4.

MARCHETTI, Anne-Marie. (2002), "Carceral Impoverishment: Class Inequality in the French Penitentiary". Ethnography, vol. 3, no 4, pp. 416-434.

MUCCHIELLI, Laurent e ROBERT, Philippe (eds.). (2002), Crime et Sécurité. L'État des Savoirs. Paris, La Découverte.

OBSERVATOIRE INTERNATIONAL DES PRISONS. (2003), Les Conditions de Détention en France. Rapport 2003. Paris, La Découverte.

PALLE, Christophe e GODEFROY, Thierry. (1999), Cô̂ts du Crime. Une Estimation Monétaire des Infractions en 1996. Guyancourt, CESDIP.

PEDRO, Antonio (ed.). (2003), Prisões na Europa. Um Debate que Apenas Começa. Oeiras, Celta Editora.

RAND, Michael. (1997), Criminal Victimization in the United States, 1994. Washington, Bureau of Justice Statistics.

ROBERT, Philippe. (2002), L'Insécurité en France. Paris, Repères.

e POTTIER, Marie-Laure. (1997), “'On ne se Sent plus en Sécurité': Délinquance et Insécurité, une Enquête sur Deux Décennies". Revue Française de Science Politique, vol. 47, no 6 , pp. 707-740.

ROUILLAN, Jann-Marc. (2004), “Chroniques Carcérales”, in Lettres à Jules. Marseillle, Agone.

SERRE, Delphine. (2001), “La Judiciarisation en Actes: Le Signalement D”Enfants en Danger'”. Actes de la Recherche en Sciences Sociales, vols. 136-137, pp. 70-82.

SIMON, David e BURNS, Edward. (1997), The Corner: A Year in the Life of an Inner-City Neighborhood. New York, Broadway Books.

SIMONNOT, Dominique. (2003), Justice en France. Une Loterie Nationale. Paris, Éditions de La Martinière.

STETTINGER, Vanessa. (2003), Funambules de la Précarité. Vendeurs de Journaux et Mendiants du Métro Parisien. Paris, PUF.

TOURNYOL DU CLOS, Lorraine. (2002), “Les Statistiques Incertaines de la Délinquance". Futuribles, no 274 , pp. 25-34.

WACQUANT, Loïc. (2004a), Deadly Symbiosis: Race and the Rise of Neoliberal Penality. Cambridge, Polity Press. 
. (2004b). “Sobre a 'Janela Quebrada' e Alguns Outros Contos sobre Segurança Vindos da América". Revista Brasileira de Ciências Criminais, no 46, pp. 228-251.

ZIMRING, Franklin E. e HAWKINS, Gordon. (1995), Incapacitation: Penal Confinement and the Restraint of Crime. New York, Oxford University Press.

\section{ABSTRACT}

\section{The French Prison System Aberration}

An analysis of the French prison system's ebullience since 2001 shows that to use incarceration as a social vacuum cleaner in order to rid society of the dregs resulting from the economic transformations of neoliberalism is in fact an aberration. Not only do French crimes rates fail to justify the boom in the country's prison population, but comparative criminology confirms that there is no correlation between the incarceration rate and the crime rate. Automatic recourse to confinement in order to quash urban disorder is a remedy that nearly always aggravates the ill it is supposed to cure. It reinforces economic marginalization, social alienation, and the convicts' feeling of injustice, since prisons disproportionately affect the economically and culturally most vulnerable social categories. It is unrealistic to treat misdemeanors with such a gross and ineffective instrument as imprisonment, and it is urgent to reconnect the discussion on delinquency to the broad social issue of this century that this discussion conceals: the emergence of de-socialized wage-earners, the social insecurity vector, and material and mental deterioration.

Key words: France; prison system; crime 


\section{Loïc Wacquant}

\section{RÉSUMÉ}

\section{L'Aberration Carcerale a la Française}

L'analyse de la subite boulimie carcérale affichée par la France depuis 2001 montre que se servir de la prison à la manière d'un aspirateur social pour nettoyer les scories des transformations économiques apportées par le néolibéralisme est une aberration. Outre que l'évolution de la criminalité en France ne justifie pas l'essor fulgurant de sa population carcérale, la criminologie comparée établit qu'il n'existe nulle part de corrélation entre taux d'emprisonnement et niveau de la criminalité. Le recours réflexe à l'incarcération pour juguler les désordres urbains est un remède qui aggrave bien souvent le mal qu'il est censé guérir en renforçant la marginalité économique, l'aliénation sociale et le sentiment d'injustice des condamnés car la contention carcérale frappe disproportionnellement les catégories sociales les plus fragiles économiquement et culturellement. Il est irréaliste de prétendre traiter les illégalismes mineurs avec un outil aussi grossier et inefficient que la prison et il est urgent de reconnecter le débat sur la délinquance avec la question sociale majeure du siècle naissant à laquelle il fait aujourd'hui écran: l'avènement du salariat désocialisé, vecteur d'insécurité sociale et de précarisation matérielle et mentale.

Mots-clé: France; système pénitentiaire; crime 